\title{
EFEKTIVITAS PROGRAM KEMITRAAN PETERNAKAN SAPI DI KABUPATEN LAMPUNG SELATAN
}

\section{EFFECTIVENESS OF CATTLE BREEDING PARTNERSHIP PROGRAM IN LAMPUNG SELATAN REGENCY}

\author{
Sri Handayani*, Irmayani Noer \\ Politeknik Negeri Lampung \\ *E-mail: sri.handayani84@polinela.ac.id \\ (Diterima 6-12-2020; Disetujui 2-1-2021)
}

\begin{abstract}
ABSTRAK
Persoalan kebijakan impor sapi bakalan menuntut para feedloter untuk melakukan pembiakan dimana membutuhkan waktu cukup panjang. Keterbatasan kandang serta risiko usaha pembiakan bagi feedloter, serta keterbatasan modal dan teknologi bagi peternak sapi menjadi dasar dilaksanakan kemitraan antara feedloter dengan peternak. Tujuan penelitian ini adalah menganalisis efekitivitas kemitraan peternakan sapi rakyat di Kabupaten Lampung Selatan. Metode penelitian yang akan digunakan adalah metode survai tepatnya di 2 Kecamatan sentra peternakan sapi terbesar yaitu Kecamatan Sidomulyo dan Tanjungsari Kabupaten Lampung Selatan. Rasio efektivitas mempergunakan metode statistik sederhana perbandingan antara realisasi dan target. Selanjutnya kriteria efektivitas merujuk pada Litbang Depdagri. Hasil dan pembahasan menunjukkan bahwa pelaksanaan program kemitraan peternakan sapi rakyat / breeding di Kabupaten Lampung Selatan ditinjau dari segi input cukup efektif dijalankan dengan rasio efektivitas $82,5 \%$. Dari segi proses dan output, pelaksanaan kemitraan sudah efektif dijalankan yaitu sebesar $90,6 \%$ dan $92 \%$.
\end{abstract}

Kata Kunci : Kemitraan, Peternakan Sapi, Efektivitas

\section{ABSTRACT}

The issue of feeder cattle import policy requires feedlots to carry out breeding which requires a long time. Limitations of cages and the risk of breeding business for feedlots, as well as limited capital and technology for cattle breeders are the basis for the partnership between feedlots and breeders. The purpose of this research are to analyze the effectiveness of the community cattle breeding partnership in South Lampung Regency. The research method that will be used is a survey method to be precise in the 2 biggest cattle breeding centers, namely Sidomulyo and Tanjungsari Districts, South Lampung Regencies. The effectiveness ratio uses a simple statistical method of comparison between the realization and the target. Furthermore, the effectiveness criteria refer to the Ministry of Home Affairs Research and Development. The results and discussion show that the implementation of the community cattle breeding partnership program in South Lampung Regency in terms of input is quite effective with an effectiveness ratio of $82.5 \%$. In terms of process and output, the implementation of the partnership has been effectively carried out, namely $90.6 \%$ and $92 \%$.

Keywords: Partnership, Cattle Farming, Effectiveness

\section{PENDAHULUAN}

Kebijakan impor sapi bakalan telah diputuskan pemerintah guna memenuhi kebutuhan pasokan daging merah dan menekan harga daging di pasaran. Pada tahun 2016, populasi sapi mencapai 16,6 


\section{EFEKTIVITAS PROGRAM KEMITRAAN PETERNAKAN SAPI \\ DI KABUPATEN LAMPUNG SELATAN \\ Sri Handayani, Irmayani Noer}

juta ekor (naik 3,72\%) dan tambahan impor daging sapi 160,7 ribu ton (naik $38,8 \%$ ). Sementara itu, nilai impor daging sapi pada 2017 mencapai US\$ 466,8 juta lalu naik 28,7\% pada 2018 menjadi US\$ 600,8 juta (Kementerian Pertanian, 2018). Namun, untuk menjaga kestabilan populasi sapi dalam negeri, Kementerian Perdagangan mewajibkan para importir atau pengusaha sapi bakalan dan siap potong (feedloter) membangun peternakan untuk pengembangbiakan/breeding (Kementerian Perdagangan, 2016).

Persoalan yang terjadi adalah usaha pembiakan dilakukan dalam waktu yang cukup panjang (5-7 tahun/periode), sementara usaha penggemukan hanya dalam jangka waktu empat bulan/periode. Hal ini, sesuai dengan penjelasan UU No. 18/2009 jo. 41/2014 tentang PKH bahwa sapi betina produktif adalah sapi yang telah melahirkan kurang dari 5 kali atau umur dibawah 8 tahun. Artinya, sapi betina hanya bisa dipotong apabila telah melewati 5 kali fase melahirkan.

Kebijakan pola produksi pembiakan/breeding ini berpengaruh pada cash flow usaha feedloter, dimana usaha penggemukan lebih cepat perputarannya dibanding dengan usaha pembiakan yang membutuhkan jangka waktu relatif panjang untuk memperoleh keuntungan. Apabila feedloter memiliki kapasitas kandang 10.000 ekor, dalam kondisi normal akan mampu melakukan importasi sapi bakalan sebanyak 30.000 ekor dan sapi indukan sebanyak 6.000 ekor dalam setahun. Jika kapasitas kandang yang dimiliki tidak bertambah, maka pada tahun berikutnya importasi sapi bakalan penggemukan harus dikurangi akibat jumlah sapi indukan yang dipelihara akan terakumulasi menjadi 11.100 ekor (Tawaf, 2018). Hal ini akan menjadi persoalan serius karena untuk tahun berikutnya populasi indukan impor yang dipelihara sudah melebihi jumlah populasi sapi penggemukan dan fasilitas kandang yang ada tidak dapat menampung sapi penggemukan. Dalam hal ini jumlah sapi indukan impor dan keturunannya memerlukan luasan kandang sekitar tiga kali lipat dari usaha penggemukan. Sementara di sisi lain, pengusaha memiliki keterbatasan dalam kepemilikan kandang/lahan untuk bertambah.

Langkah integrasi ternak dapat dilakukan melalui pola kemitraan antara pihak perusahaan dan petani-ternak (Suharto, 2004). Terkait dengan fenomena tersebut, tentu menjadi objek kajian yang menarik untuk diuraikan 
terutama menganalisis bagaimana konsep kemitraan, kelayakan usaha dan efektivitas kemitraan peternakan sapi.

Pola kemitraan peternakan sapi telah dilakukan di Provinsi Lampung dengan sebelas feedloter (perusahaan penggemukan sapi potong).

Beberapa feedloter yang melaksanakan kemitraan dengan pola peternakan rakyat adalah PT Juang Jaya Abdi Alam, PT Great Giant Livestock, dan lainnya. Pemerintah Daerah Provinsi Lampung memiliki target menjadi lumbung ternak nasional dengan salah satu sentra peternakan sapi ada di Kabupaten Lampung Selatan. Berdasarkan hasil penelitian Komoditas Produk Jasa Unggulan Bank Indonesia (2018) menunjukkan bahwa Kabupaten Lampung Selatan berpotensi dan prospektif dalam pengembangan peternakan sapi dibandingkan dengan peternakan ayam dan lainnya dengan skor 0,0777. Badan Pusat Statistik Lampung (2019) mendata populasi ternak sapi potong pada 2018 yakni 827.217 ekor dan pada 2019 sebanyak 819.571 ekor. Sangat jelas hal ini menjadi peluang besar dalam pengembangan bisnis peternakan sapi.
Persoalan yang terjadi di Kabupaten Lampung Selatan adalah pola peternakan sapi masih berjalan skala usaha rakyat yang terkait dengan usahatani lainnya. Penerapan manajemen dan teknologi masih bersifat konvensional, modal terbatas, mengandalkan hijauan makanan ternak (HMT) dari alam, dan rata-rata kepemilikan 2-3 ekor, sehingga efisiensi sulit dicapai (Mandaka dan Hutagaol, 2005). Peternak kurang menargetkan produktivitas ternak sapi yang akan dicapai dan kurang memperhitungkan input dan output usaha ternaknya (Yusdja, dkk., 2001). Melihat dari perkembangan yang terjadi, kemitraan pembibitan sapi sangat penting keberadaannya di kalangan para peternak sapi. Kemitraan diperlukan mengingat ketergantungan Indonesia terhadap daging sapi impor akan meningkat, dan kebutuhan konsumsi dalam negeri akan terus dipasok oleh daging impor (Handayani, dkk, 2016). Kemitraan dengan feedloter diharapkan menjadi salah satu solusi untuk mengatasi keterbatasan peternak dalam mengembangkan usaha ternak pembibitan sapi potong. Dengan melakukan kemitraan usaha lebih efektif dan efisien, serta memberikan 


\section{EFEKTIVITAS PROGRAM KEMITRAAN PETERNAKAN SAPI \\ DI KABUPATEN LAMPUNG SELATAN \\ Sri Handayani, Irmayani Noer}

keuntungan bagi pelaku usaha (Fitri, $d k k$, 2018). Permasalahan struktur agribisnis sapi potong yang tidak proporsional ini perlu dianalisis secara cermat.

Untuk itu diperlukan evaluasi secara mendalam dan menyeluruh terhadap program kemitraan peternakan sapi rakyat agar dapat diketahui tingkat efektivitas kemitraan. Bertitik tolak dari latar belakang, maka dirumuskan pokok masalah adalah: bagaimana efektivitas Program Kemitraan Peternakan Sapi Rakyat di Kabupaten Lampung Selatan.

Tujuan penelitian ini adalah untuk menganalisis efekitivitas kemitraan peternakan sapi rakyat di Kabupaten Lampung Selatan.

\section{METODE PENELITIAN}

Penelitian dilakukan di Kabupaten Lampung Selatan tepatnya di 2 Kecamatan sentra peternakan sapi terbesar Kecamatan Sidomulyo dan Tanjungsari. Pemilihan lokasi penelitian dilaksanakan dengan Purposive, hal ini didasarkan pada pertimbangan lokasi tersebut menjadi sentra peternakan sapi yang telah melaksanakan kemitraan dengan perusahaan feedloter. Metode pengumpulan data melalui observasi, survey, indepth interview dan FGD, dengan responden terdiri dari: peternak sapi sejumlah 30 orang. Kegiatan penelitian akan dilakukan mulai Bulan Juni hingga November 2020.

Metode penelitian yang digunakan adalah metode survai yang merupakan teknik penelitian dan pengumpulan data pada suatu populasi tertentu dengan tujuan untuk menjaring sejumlah data tertentu dengan tujuan generalisasi. yaitu penelitian yang dilakukan untuk mendapatkan data dari tempat tertentu yang alamiah (bukan buatan) dan peneliti melakukan perlakuan dalam pengumpulan data, misalnya dengan mengedar kuesioner, tes, wawancara terstruktur dan sebagainya (Sugiyono, 2006). Selanjutnya, menurut sifatnya penelitian ini adalah penelitian kualitatif dan kuantitatif yang memusatkan pada pengumpulan data kuantitatif yang berupa angka-angka untuk kemudian dianalisis dengan menggunakan analisis statistika (Mardikanto, 2009).

Data yang diperlukan dalam penelitian adalah data primer dan data sekunder. Data primer diperoleh melalui wawancara langsung dengan peternak sapi dan perusahaan feedloter dengan menggunakan daftar pertanyaan yang sudah disiapkan. Data sekunder diperoleh dari instansi terkait yaitu Dinas Peternakan Kabupaten Lampung Selatan, 
Badan Pusat Statistik, literatur atau penelitian sebelumnya. Responden pada penelitian ini adalah peternak sapi yang melaksanakan kemitraan dengan perusahaan feedloter sejumlah 30 orang. Teknik pengambilan sampel menggunakan teknik purposive sampling dengan dasar peternak yang aktif menjalankan kemitraan.

Selanjutnya, untuk mngetahui efektif atau tidaknya Program Kemitraan Peternakan sapi di Kabupaten Lampung Selatan digunakan rasio efektivitas. Menurut Sugiyono (2012), rasio efektivitas mempergunakan metode statistik sederhana dengan formula sebagai berikut:

Efektivitas $=\frac{\text { Realisasi }}{\text { Target }} \times 100 \%$

Pengukuran tingkat efektivitas pada variabel input, proses, dan output dilakukan pada masing-masing indikator. Setelah mendapatkan tingkat efektivitas dari masing-masing indikator pada variabel input, proses, dan output selanjutnya dilakukan pengklasifikasian tingkat efektivitas seperti pada Tabel 1.
Tabel 1. Kriteria Efektivitas dari Litbang Depdagri

\begin{tabular}{ll}
\hline Kriteria & \multicolumn{1}{c}{ Keterangan } \\
\hline$<60 \%$ & Tidak efektif \\
$60 \%-79,99 \%$ & Kurang efektif \\
$80 \%-89,99 \%$ & Cukup efektif \\
$90 \%-100 \%$ & Efektif \\
$>100 \%$ & Sangat efektif \\
\hline Sumber: & Keputusan Menteri Dalam Negeri \\
& Nomor 690.900 .327 Tahun 1996
\end{tabular}

\section{HASIL DAN PEMBAHASAN}

$\begin{array}{crr}\text { Hasil } & \text { analisis } & \text { deskriptif } \\ \text { menunjukkan } & \text { tingkat } & \text { efektivitas }\end{array}$ kemitraan usaha ternak sapi antara PT Juang Jaya dengan petani-peternak di Kabupaten Lamoung Sekatan tergolong kategori cukup efektif dengan rata-rata skor 3,20 atau $64,05 \%$. Semua indikator valid berpengaruh nyata pada taraf signifikansi $5 \%$ sebagai pengukur konsruk efektivitas kemitraan usaha ternak sapi potong, yang dapat dijelaskan sebagai berikut:

1) Efektivitas variabel input

Efektivitas variabel input Program Kemitraan peternakan sapi rakyat / breeding di Kabupaten Lampung Selatan diketahui berdasarkan empat indikator yaitu sosialisasi program, tingkat ketepatan sasaran program, tujuan program dan penjelasan persyaratan kredit. 


\section{EFEKTIVITAS PROGRAM KEMITRAAN PETERNAKAN SAPI \\ DI KABUPATEN LAMPUNG SELATAN \\ Sri Handayani, Irmayani Noer}

2) Efektivitas variabel proses

Efektivitas variabel proses Program

Kemitraan peternakan sapi rakyat/ breeding di Kabupaten Lampung Selatan diketahui berdasarkan enam indikator yaitu persyaratan pencairan kredit, waktu pencairan kredit, ketepatan waktu pelunasan, kecepatan respon petugas, monitoring dan evaluasi.

3) Efektivitas variabel output
Efektivitas variabel output Program Kemitraan peternakan sapi rakyat/ breeding di Kabupaten Lampung Selatan diketahui berdasarkan tiga indikator yaitu pencapaian tujuan, pendapatan dan penyerapan tenaga kerja.

Distribusi frekuensi jawaban orang responden dari masing-masing indikator variabel input efektivitas Program Kemitraan dapat dilihat pada Tabel 2.

Tabel 2. Rekapitulasi Distribusi Frekuensi Jawaban Responden dari Masing-masing Indikator Variabel Input Efektivitas Program Kemitraan Peternakan Sapi di Kabupaten Lamung Selatan

\begin{tabular}{|c|c|c|c|}
\hline No & Indikator & Jumlah responden & Persentase \\
\hline 1 & Variabel Input & & \\
\hline $\mathrm{a}$ & Sosialisasi program & 25 & $83 \%$ \\
\hline $\mathrm{b}$ & Tingkat ketepatan sasaran & 24 & $80 \%$ \\
\hline $\mathrm{c}$ & Tujuan program & 24 & $80 \%$ \\
\hline \multirow[t]{2}{*}{$\mathrm{d}$} & Penjelasan persyaratan kemitraan & 26 & $87 \%$ \\
\hline & Rata-rata & & $82,5 \%$ \\
\hline $\mathrm{a}$ & Persyaratan sapi keluar & 28 & $93 \%$ \\
\hline $\mathrm{b}$ & Waktu pengiriman sapi & 28 & $93 \%$ \\
\hline $\mathrm{c}$ & Ketepatan waktu pembayaran & 25 & $83 \%$ \\
\hline$d$ & Kecepatan respon petugas & 28 & $93 \%$ \\
\hline e & Monitoring & 27 & $90 \%$ \\
\hline $\mathrm{b}$ & Pendapatan & 25 & $83 \%$ \\
\hline \multirow[t]{2}{*}{$\mathrm{c}$} & Penyerapan tenaga kerja. & 30 & $100 \%$ \\
\hline & Rata-rata & & $92 \%$ \\
\hline
\end{tabular}

Hasil perhitungan diperoleh bahwa tingkat efektivitas pelaksanaan Program Kemitraan peternakan sapi rakyat/ breeding di Kabupaten Lampung Selatan ditinjau dari variabel input adalah sebesar 82,5 persen berada pada interval koefisien efektivitas dari 80\%-89,99\%. Hal ini berarti tingkat efektivitas variabel input masuk dalam katagori cukup efektif. Pada variable proses, hasil perhitungan efektivitas kemitraan adalah sebesar 90,6 persen berada pada interval 90 persen-100 persen. Hal ini berarti tingkat efektivitas variabel proses masuk dalam katagori efektif. Hasil perhitungan efektivitas kemitraan ditinjau dari variabel output adalah sebesar 92 persen berada pada interval 90 persen-100 persen. Hal ini berarti tingkat efektivitas variabel output masuk dalam katagori 
efektif.

Berdasarkan hasil analisis data efektivitas kemitraan, maka point perbaikan yang dapat dilakukan adalah :

a. Pelaksanaan sosialisasi program sebaiknya terkoordinir dengan baik sebagai model sosialisasi yang dapat disampaikan kepada calon mitra

b. Konsep menggunakan media sosialisasi seperti buku saku agar dapat mudah dipahami mitra

c. Pemberian tenggang waktu pembayaran anak sapi dikarenakan tidak semua peternak memiliki keuangan yang sama.

d. Adanya batas bobot minimum dan maksimum yang menjadi rujukan dalam pembayaran anak sapi.

\section{KESIMPULAN DAN SARAN}

\section{Kesimpulan}

Berdasarkan hasil pembahasan yang dilakukan, maka didapat kesimpulan: Pelaksanaan Program Kemitraan Program Kemitraan peternakan sapi rakyat/breeding di Kabupaten Lampung Selatan ditinjau dari segi input cukup efektif dijalankan. Dari segi proses dan output, pelaksanaan kemitraan sudah efektif dijalankan.

\section{Saran}

Berdasarkan kesimpulan, maka saransaran yang dapat diajukan adalah sebagai berikut:

1) Dari segi input, agar pelaksanaan kegiatan sosialisasi tentang program dan penjelasan tentang persyaratan kemitraan dapat dikoordinasi dengan baik dan semua peserta menghadiri kegiatan sosialisasi yang dilaksanakan.

2) Dari segi proses dan output, agar persyaratan kemitraan yang harus dipenuhi menyesuaikan dengan kondisi peternak, dan diberikan alternatif lain apabila terdapat salah satu prasyarat sulit untuk dilengkapi oleh mitra binaan. Kontrol terhadap ketepatan waktu peternak dalam melunasi pembayaran anak sapi juga perlu dikaji ulang.

\section{DAFTAR PUSTAKA}

Badan Pusat Statistik. 2019. Populasi Ternak (Sapi) Menurut Kabupaten/Kota Di Provinsi Lampung, 2014-2018. Badan Pusat Statistik Lampung. Bandar Lampung.

Bank Indonesia. 2018. Ringkasan Eksekutif Komoditas Produk Jasa Unggulan Usaha Mikro Kecil Dan Menengah Tahun 2017 Di Provinsi Lampung. Bank Indonesia. Bandar Lampung.

Direktorat Jenderal Peternakan. 2007. Statistik Peternakan. Direktorat 
Jenderal Peternakan, Jakarta.

Fitri, A., Harianto, H. and Asmarantaka, R. W. (2018) 'The Effects of Partnerships on the Efficiency of Mustard Farming at Megamendung District', Jurnal Manajemen dan Agribisnis, 15(1), pp. 12-22. doi: 10.17358/jma.15.1.12.

Hafsah, M.J. 2006. Kemitraan Usaha: Konsepsi Dan Strategi. Departemen Pertanian. Jakarta.

Handayani, Sri. 2014. Sistem Kebersamaan Ekonomi Sebagai Dasar Kemitraan Tambak Udang. Jurnal Bisnis Dan Manajemen, 11(1).

Handayani,S. Fariyanti, A, dan Nurmalina, R. 2016. Swasembada Daging Sapi Analisis Simulasi Ramalan Swasembada Daging Saoi Di Indonesia. Sosiohumaniora, 18 (1): $61-70$

Handayani, Sri. 2016. Analisis Keuntungan Dan Sensitivitas Umkm Makanan Ringan Berbahan Baku Singkong Di Kecamatan Gedong Tataan. In Prosiding Seminar Nasional Pengembangan Teknologi Pertanian.

Handayani, Sri, Fitriani, dan Yolandika, C. 2018. Pengantar Koperasi Untuk Perguruan Tinggi. Up Politeknik Negeri Lampung. Isbn 978-6025730-14-6.

Kementerian Pertanian. 2017. Konsumsi Periode Tahun 2016. Newsletter Data Makro. Sekretariat Ditjen PKH.

Kementerian Pertanian. 2018. Populasi Sapi Potong Dan Kerbau (20132017e).

Https://Databoks.Katadata.Co.Id/D atapublish/2018/04/13/BerapaPopulasi-Sapi-Potong-Dan-KerbauDi-Indonesia. Diakses Tanggal 10 Maret 2020.

Kementerian Perdagangan. 2016. Analisis Outlook Pangan 2015$2019 . \quad$ Pusat Kebijakan
Perdagangan Dalam Negeri Badan Pengkajian Dan Pengembangan Kebijakan Perdagangan Kementerian Perdagangan. Jakarta. Mandaka, S. dan Hutagaol, M.P. 2005. Analisis Fungsi Keuntungan, Efisiensi Ekonomi Dan Kemungkinan Skema Kredit Bagi Pengembangan Skala Usaha Peternakan Sapi Perah Rakyat Di Kelurahan Kebon Pedes, Kota Bogor. Jurnal Agro Ekonomi, 23: 191-208.

Keputusan Menteri Dalam Negeri Nomor 690.900.327 Tahun 1996 Tentang Pedoman Penilaian Kinerja Keuangan.

Mardikanto. 2009. Sistem Penyuluhan Pertanian. Pusat Pengembangan Agrobisnis dan Perhutanan Sosial. Sebelas Maret University Press. Surakarta

Suardika, P., Ambarawati, I. G. A. A., \& Sudarma, I. M. (2015). Efektivitas Kemitraan Usaha Ternak Sapi Potong Terhadap Pendapatan Petani-Peternak Di Kabupaten Timor Tengah Utara Provinsi Nusa Tenggara Timur. Jurnal Manajemen Agribisnis (Journal Of Agribusiness Management). Vol. 3, No. 2, Oktober 2015

Sugiyono. 2009. Statistik Untuk Penelitian. Alfabeta. Bandung.

2012. Metode Penelitian Bisnis. Bandung: Alfabeta.

Suharto. 2004. Pengalaman Pengembangan Usaha Sistem Integrasi Sapi-Kelapa Sawit Di Riau. Hlm. 57-63 Prosiding Lokakarya Nasional Sistem Integrasi Kelapa Sawit-Sapi, Bengkulu, 9-10 September 2003. Departemen Pertanian Bekerja Sama Dengan Pemerintah Provinsi Bengkulu Dan Pt Agricinal. 
Tangkilisan, Nogi Hessel. 2005. Manajemen Publik. Pt. Gramedia Widiasarana Indonesia. Jakarta.

Tawaf, Rochadi. 2018. Analisis Usaha Pembiakan Sapi Potong Pola Kemitraan Antara Korporasi Dengan Peternak Rakyat. Jurnal Ilmu-Ilmu Sosial Dan Humaniora.
Vol. 20, No. 1, Maret 2018: 45 - 56 Winarso, B., Sajuti, R. Dan Muslim, C. (2005). Tinjauan Ekonomi Ternak Sapi Potong Di Jawa Timur. Forum Penelitian Agro Ekonomi 23 (1): 61-71. 